\title{
Prognostic factors for survival and surgical complications in Whipple's pancreatoduodenectomy during a 10-year experience
}

\author{
Factores de pronóstico de sobrevida y complicaciones quirúrgicas en la \\ pancreaticoduodenectomía de Whipple durante 10 años de experiencia
}

\author{
Francisco Reyna-Sepúlveda, Gerardo Muñoz-Maldonado, Edelmiro Pérez-Rodríguez, \\ Fabiola Hernández-Trejo, Asdrúbal Guevara-Charles and Marco Hernández-Guedea* \\ Department of Surgery, University Hospital "Dr. José Eleuterio González", Autonomous University of Nuevo León, México
}

\begin{abstract}
Background: Periampullary neoplasms account for over 30,000 cancer-related deaths per year in the United States. Pancreaticoduodenectomy $(P D)$ is considered the surgical standard and is the only curative treatment option for these pathologies. Objective: The objective of this study was to report the prognostic factors in survival and surgical complications in PD. Materials and Methods: $A$ total of 178 cases are reported, several variables were reviewed and the same surgical techinique was used by the same surgeon. Results: $A$ total of $151 P D$ were reviewed. The most common initial symptoms were jaundice, $111(73 \%)$, abdominal pain, 20 (13\%), and oral intolerance, 10 (6\%). Poor prognostic factors for survival were the presence of a previous pathology, days of hospitalization, positive margins, and weight loss. Discussion: With the experience gained, a decrease in surgical time, intraoperative bleeding, and transfusions performed was achieved. Our complication rate remained at $20 \%$, lower than that reported in literature. Conclusion: $P D$ is the only option of cure for patients with pancreatic and periampullary tumors. This procedure has been linked to high morbidity and mortality even in high-volume centers. A pancreatic fistula is the most feared complication; therefore, multiple pancreatojejunostomy techniques have been described in literature. It is important to continue reporting these cases to reach a consensus on this technique.
\end{abstract}

KEY WORDS: Pancretoduodenectomy. Surgical technique. Perioperative management.

\section{Resumen}

Antecedentes: Las neoplasias periampulares suponen más de 30.000 muertes relacionadas con el cáncer por año en loșEE. UU. La pancreaticoduodenectomía (PD) se considera el estándar quirúrgico y es la única opción de tratamiento curativo parāesta enfermedad. Objetivo: Reportar los factores de pronóstico en la supervivencia y las complicaciones quirúrgicas de la PD. Método: Se reportaron 178 casos; se revisaron varias variables y se utilizó la misma técnica quirúrgica por el mismo cirujano. Resultados: Se revisaron 151 DP. Los síntomas iniciales más comunes fueron ictericia (111; 73\%), dolor abdominal (20; 13\%) e intolerancia oral $(10 ; 6 \%)$. Los factores de pronóstico para la supervivencia fueron la presencia de patología previa, los días de hospitalización, los márgenes positivos y la pérdida de peso. Discusión: Con la experiencia adquirida, se logró una disminüción del tiempo quirúrgico, del sangrado intraoperatorio y de las transfusiones realizadas. Nuestra tasa de complicaciones se mantuvo en un 20\%, inferior a la reportada en la literatura. Conclusión: La PD es la única opción de curación para los pacientes con tumores pancreáticos y periampulares. Este procedimiento se ha relacionado con una alta morbilidad y mortalidad incluso en ceñtros de alto volumen. La fístula pancreática es la complicación más temida, por lo que se han descrito numerosas técnicas de pancreatoyeyunostomía. Es importante seguir informando de estos casos para llegar a un consenso sobre esta técnica.

PALABRAS CLAVE: Pancretoduodenectomía Técnica quirúrgica. Manejo perioperatorio.

Correspondence:

*Marco Hernández-Guedea

Francisco I. Madero and Av. Gonzalitos, s/n

Date of reception: 12-06-2018

Monterrey, Nuevo León, México

Date of acceptance: 14-08-2018

E-mail: marco.hernandezgd@uanl.edu.mx

DOI://dx.doi.org/10.24875/CIRU.18000526

Cir Cir. 2019;87:205-210

Contents available at PubMed www.cirugiaycirujanos.com 


\section{Background}

Periampullary cancer accounts for over 30,000 cancer-related deaths per year in the United States ${ }^{1}$. The incidence increases to 87.2 cases per 100,000 in patients over 80 years of age. Risk factors for pancreatic cancer are unknown; however, it is considered that some may be coffee, tobacco, and a history of chronic pancreatitis or diabetes ${ }^{2}$.

Survival in periampullary bile duct cancer is $20-25 \%$, for ampullary disease, it is $30-40 \%$ and for duodenal tumors, $50-60 \%$; for this reason, some surgeons recommend only palliative care ${ }^{3,4}$. At diagnosis $>80 \%$ are considered unresectable with a 5 -year survival after pancreaticoduodenectomy (PD) of $15-20 \%^{5}$.

PD is considered the surgical standard for biliary, periampullary duodenal and pancreatic head neoplasms. It is the only curative treatment option in these pathologies. PD has an accepted low mortality rate of $3-5 \%$ with a high morbidity of $40-50 \%$ due to pancreatic fistulas and delayed gastric emptying ${ }^{6-8}$.

Some long-term consequences of PD are malnutrition associated to weight loss, malabsorption, and chronic need of supplementation due to a deficiency of micronutrients that are normally absorbed in the proximal intestine ${ }^{9}$. Pancreatic fistula is the most feared complication; therefore, multiple techniques of pancreatojejunostomy anastomosis have been described. No technique has proven to be a permanent solution to this problem.

\section{Objective}

The objective of this study was to report the prognostic factors in survival and surgical complications in PD.

\section{Materials and methods}

This was a retrospective cohort study of cases retrieved from the Department of Statistics of the "Dr. José Eleuterio González" University Hospital in Monterrey, Mexico. All PD cases from 2005 to 2014 were reviewed. This article does not contain any studies with human subjects performed by any of the authors, no informed consent was required, and no identifying information is included. Patients with resectable tumors defined by the absence of distant metastases and without local extension to the celiac

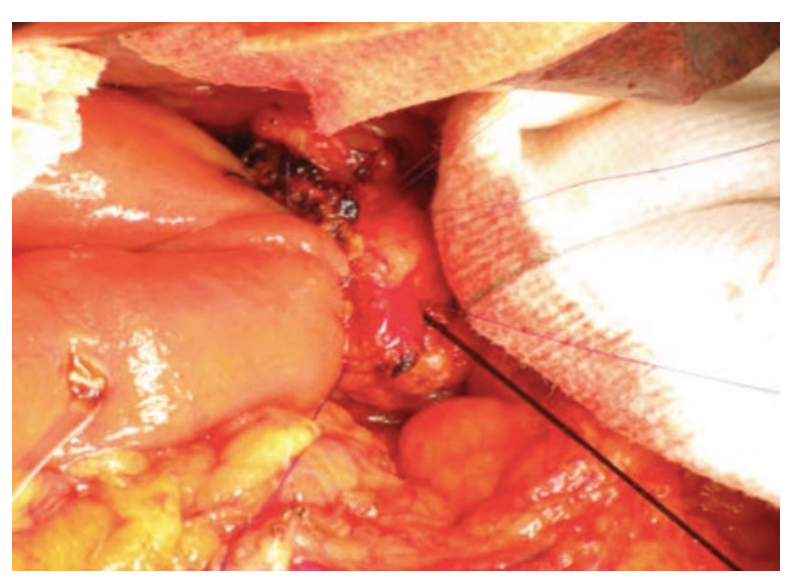

Figure 1. Terminoterminal telescoped pancreatojejunostomy.

axis, hepatic artery, and the superior mesenteric tery were included. Patients treated with derivative surgery or with the absence of a clinical record were excluded. We obtained 178 cases, of which 27 were excluded resulting in a total of 151 patients who underwent PD. This was a single surgeon and single-center study.

Other variables reviewed were age, gender, initial symptoms, medical history, comorbidities, hospital stay, pre-operative studies, number of transfusions, days in intensive care, classification of the American Society of Anesthesiologists (ASA), surgical time clinical stage, post-operative complications, morbidities, and post-operative mortality.

With regard to the surgical technique, all patients were approached with a bilateral subcostal laparotomy. Resectability without vascular invasion or extrahepatic disease was confirmed during surgery. The Kocher maneuver was performed and the common bile duct was divided. Subsequently, an anterior plane is created, the portal vein and superior mesenteric artery are dissected, and the distal stomach is divided preserving the pylorus. Afterward, the distal jejunum was divided near the ligament of Treitz and the previous pancreas was divided in front of the portal vein; subsequently, the branches of the superior mesenteric vein are ligated and the hepatic artery is dissected. Three anastomoses are performed:

(1) antecolic terminoterminal hepaticojejunostomy; (2) terminoterminal telescope pancreatojejunostomy, which was performed in all cases with duct mucosa and pancreatic duct cannulation (Fig. 1), with additional intermittent circumferential points to the jejuntum, which were reinforced with a second circumferential layer and placement of a pancreatic duct catheter; and (3) laterolateral gastrojejunostomy. Selection biastwas 
avoided by the patient list provided by the statistics department, performance bias with all the procedures done by a single surgeon, and reporting bias was avoided by the revision of surgery professors.

For statistical analysis, SPSS version 22 (IBM, Armonk, NY, USA) was used. The variables were compared using the Mann-Whitney U-test and the Chi-square test with a statistical significance of $p<0.05$.

\section{Results}

A total of 151 cases with a mean age of 55 years and a total of 91 men (60\%) and 60 women (40\%) were reviewed. The mean body mass index was $25 \mathrm{~kg} / \mathrm{m}^{2}$, with 76 (50\%) patients above 25. Regarding the clinical history, a diagnosis of Type 2 diabetes mellitus was found in 50 (33\%) patients and hypertension in $40(26 \%)$, and 15 patients had a previously diagnosed carcinoma.

The most common symptoms were jaundice in $110(73 \%)$, abdominal pain in $20(13 \%)$, and oral intolerance in $10(6 \%)$. Of all patients with jaundice and abdominal pain, $63 \%$ also presented oral intolerance. Regarding pre-operative weight loss, 35 (23\%) patients had a loss of $>5 \mathrm{~kg}$, and $40(27 \%)$ patients had a high nutritional risk score greater than 3 points.

A pre-operative tumor size $>2 \mathrm{~cm}$ was reported in $50(32 \%)$ patients. Total and direct bilirubin was reported elevated in 106 (70\%) patients. Aspartate aminotransaminase increased more than twice its normal value in $55(36.6 \%)$ patients, and alanine aminotransferase increased more than twice in $40(26 \%)$ patients; finally, CA 19 was reported in 55 (36.6\%) patients. No patient underwent preoperative chemotherapy (CT) or radiotherapy (RT) and a risk of the ASA was reported in two or higher in 116 patients $(76 \%)$.

Diagnosis of ampulloma (duodenal or pancreatic head tumor) was done in a total of 131 (86.5\%) patients, five cholangiocarcinoma, 10 insulinomas, and five neuroendocrine tumors. The mean operating time was $248 \mathrm{~min}$ with a mean bleeding volume of $1000 \mathrm{ml}$ reported. For transfusions, only $25(16.6 \%)$ patients required three or more transfusions. $35(23 \%)$ patients required intensive care, lasting a mean of 9 days. Mean hospitalization was 11 days with 110 (73\%) patients staying $<10$ days.

As for morbidity, 30 (20\%) cases reported: 12 collections (7.9\%), 10 pancreatic fistulas (6.6\%), and 8 episodes of post-operative bleeding (5.2\%). Patients with post-operative bleeding were reoperated and patients with intra-abdominal collection were mannaged with percutaneous catheter placement. Five post-operative mortalities (3.3\%) were reported duie to pancreatic fistula and abdominal sepsis.

The pathological diagnosis of 131 patients admitted to surgery was ampulloma, from which a total of 81 patients presented duodenal adenocarcinoma an® 50 tumors included pancreatic head adenocarcinomas, cholangiocarcinomas, neuroendocrine tumors, and insulinomas. Mean tumor size was $1.5 \mathrm{~cm}$ for adenocarcinomas, $60(46 \%)$ patients had positive nodes, and positive margins were found in $15(11.5 \%)$.

In post-operative management, $60(40 \%)$ patients were followed, of which 25 received CT only, another 10 RT only, and 25 received a combination of OT. and RT. Distant metastases were found in $40(26 \%)$ patients during follow-up at 2 years. 2-year survival was $38 \%$.

Statistical analysis was done comparing the group of patients who survived and the group of patients who died (Table 1) to obtain predictors of mortality. These were the presence of a previous medical disease, days of hospital stay, post-operative margins, and weight loss.

In addition, the node-positive group and the node-negative group were compared and no statistical significance was found. Finally, the groups of patients who suffered complications versus those without complications and only days of hospital stay and weight loss were significant $(p \leq 0.05)$.

\section{Discussion}

Halsted, in 1898, was the first to successfully attempt local resection of a periampullary carcinoma. Alessandro Codivilla was the first surgeon to perform a PD. Allen Whipple subsequently modified this teechnique in 1935. This technique for handling pancreatic tumors and periampullary was complex and was associated with a very high morbidity and mortality $\frac{10}{\sigma}$.

During our 10-year experience, different aspects of this technique progressed achieving reduction in surgical times, intraoperative bleeding, and number of transfusions ${ }^{11}$. Our morbidity rate remained $20 \%$. A serious complication is post-operative bleeding, which can be managed using interventional angiography with embolization; however, in our case, due to our available resources, reoperation was cour preference.

A comparison of surgical procedures performed from 2006 to 2010 and from 2011 to 2015 was made 
Table 1. Comparison between survival and 2-year mortality during the 2-year follow-up

\begin{tabular}{|c|c|c|c|c|}
\hline Variables & 2-year survival (\%) & 2-year mortality (\%) & Survival versus mort & tality \\
\hline Patients & $106(70)$ & $45(30)$ & & $\gtrsim$ \\
\hline Mean age & 54 & 57 & ns & $\varepsilon$ \\
\hline Mean BMI, kg/m² & 24 & 26 & ns & 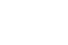 \\
\hline Comorbidities & $50(47)$ & $20(44)$ & $<0.05$ & (4) \\
\hline Initial symptoms & & & ns & $\stackrel{\longleftarrow}{\varrho}$ \\
\hline Jaundice & $70(66)$ & $40(88)$ & & $\frac{\underline{n}}{0}$ \\
\hline Pain & $20(19)$ & $5(12)$ & & 르 \\
\hline Weight loss (kg) & $10(9)$ & 0 & & 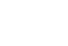 \\
\hline Others & $5(4)$ & 0 & & 4 \\
\hline Mean nutritional risk & 2.29 & 2 & ns & $\overline{0}$ \\
\hline Biliary dilatation & $40(38)$ & $20(44)$ & ns & $\frac{n}{\varepsilon}$ \\
\hline Total bilirubin & 7.9 & 7.76 & ns & ¿̄ \\
\hline Direct bilirubin & 5.11 & 4.76 & ns & $\frac{c}{d}$ \\
\hline AST & 113 & 110 & ns & $\frac{ \pm}{2}$ \\
\hline ALT & 106 & 105 & ns & $\grave{0}$ \\
\hline $\mathrm{AP}$ & 392 & 294 & ns & 드 \\
\hline Lewis antigen (CA19-9) & 57.72 & 71.02 & ns & $\stackrel{d}{\Perp}$ \\
\hline Mean ASA & 2 & 2.2 & ns & $\stackrel{+}{2}$ \\
\hline Mean surgical time, minutes & 253 & 236 & ns & $\stackrel{c}{ \pm}$ \\
\hline Mean bleeding, milliliters & 995 & 1194 & ns & s \\
\hline Transfusions, units & 0.9 & 1.6 & ns & $\cdot \frac{=}{\lambda}$ \\
\hline ICU admission & 0.5 & 1.7 & ns & 엄 \\
\hline Complications & $20(19)$ & $25(55)$ & ns & $\stackrel{0}{0}$ \\
\hline Inpatient days & 9.5 & 16.5 & $<0.05$ & 른 \\
\hline Tumor size $>2 \mathrm{~cm}$ & $50(47)$ & $25(55)$ & ns & $\frac{0}{0}$ \\
\hline Positive nodes (post-operative) & $45(42)$ & $15(33)$ & ns & $\stackrel{\underline{u}}{د}$ \\
\hline Positive margins & $10(9)$ & $5(12)$ & $<0.05$ & 인 \\
\hline Post-operative clinical phase & & & ns & $\frac{1}{U 1}$ \\
\hline $\mathrm{T} 1$ & $40(38)$ & $25(55)$ & & ع \\
\hline $\mathrm{T} 2$ & $20(19)$ & 0 & & $\overrightarrow{\widetilde{\sigma}}$ \\
\hline T3 & $40(38)$ & $15(33)$ & & $\frac{\varsigma}{\Omega}$ \\
\hline $\mathrm{T} 4$ & $5(4)$ & $5(12)$ & & "ᄑ \\
\hline Post-operative follow-up & & & & 윽 \\
\hline $\mathrm{CT}( \pm) \mathrm{RT}$ & 45 & $15(33)$ & ns & $\frac{2}{n}$ \\
\hline Weight loss, kg & 0 & 8.5 & $<0.05$ & $\subsetneq$ \\
\hline Metastases & $20(19)$ & $15(33)$ & ns & 0 \\
\hline Mean 2-year survival & & $11 \mathrm{~m}$ & ns & $\begin{array}{l}\overline{0} \\
\stackrel{2}{0}\end{array}$ \\
\hline \multicolumn{5}{|c|}{$\begin{array}{l}\text { Statistical tests were done with the Mann-Whitney U-test and Chi-square test with a significance of } p<0.05 \text {, ASA: American Society of Anesthesiologists, AST: aspartate } \\
\text { aminotransferase, ALT: alanine aminotransferase, AP: alkaline phosphatase, ICU: intensive care unit, CT: chemotherapy, RT: radiotherapy, ns: not significant, BMI: body mass index. }\end{array}$} \\
\hline
\end{tabular}


Table 2. Surgical evolution of patients in a 10-year period

\begin{tabular}{|c|c|c|c|c|}
\hline Year of surgery & Total patient & Surgical time, $\min$ & Transoperative bleeding, $\mathrm{mL}$ & Transfusions \\
\hline 2006 & 13 & 323 & 768 & 2.5 \\
\hline 2007 & 16 & 315 & 618 & 2.8 \\
\hline 2008 & 14 & 357 & 620 & 2.3 \\
\hline 2009 & 16 & 269 & 664 & 1.6 \\
\hline 2010 & 17 & 289 & 632 & 1.1 \\
\hline Total 2006-2010 & 76 & 310.6 & 660.4 & 2.06 \\
\hline 2011 & 15 & 317 & 779 & 2.3 \\
\hline 2012 & 18 & 315 & 675 & 1.7 \\
\hline 2013 & 16 & 282 & 560 & 2 \\
\hline 2014 & 12 & 190 & 267 & 0.5 \\
\hline 2015 & 14 & 250 & 700 & 1.3 \\
\hline Total 2011-2015 & 75 & 270.8 & 596.2 & 1.56 \\
\hline Improvement & 151 & -39.8 & -64.2 & -0.5 \\
\hline Statistical significance & & ns & ns & ns \\
\hline
\end{tabular}

(Table 2) and found an improvement in surgical time (-39.8 $\mathrm{min}$ ), a reduction in intraoperative bleeding $(-64.2 \mathrm{ml})$ and in the number of blood units transfused intraoperatively $(-0.5)$. Characteristically, most of our patients arrive at late stages of disease with obstructive jaundice and advanced tumor sizes ${ }^{12}$. This is why distant disease and advanced cancer stage in our post-operative patients were reported. Early diagnosis is important and a high clinical suspicion is essential in this pathology.

Our technique with duct-mucosal anastomosis and pancreatojejunal telescope anastomosis with cannulation of the pancreatic duct (Fig. 1) managed to maintain a rate of pancreatic fistula of $6.6 \%$. This technique helps decrease the rate of pancreatic fistula and leakage preventing accumulation of pancreatic secretions and anastomosis to exclude direct contact with the pancreatic juices, the most important handicap includes patients with hard pancreas which is associated to a higher fistula rate ${ }^{13}$.

Mortality in our review is $3.3 \%$. One of the most feared complications is a pancreatic fistula, which can quickly endanger the patient's life because it leads to peritonitis and severe sepsis. All patients who died before 2 years had similar symptoms and laboratory findings compared to patients with a better outcome. Factors such as personal background, post-operative complications, and surgical time were significantly different between these groups. Patients with a poor prognosis characteristically presented a significant weight loss during their post-operative evaluations.

Despite maintaining a low mortality rate, some surgeons, due to a lack of technical resources, identify an advanced stage of disease, and therefore, onty a derivative procedure can be offered. Laparoscopic PD is considered only in a subset of patients because this procedure is associated with an increased Pcidence of pancreatic fistulas ${ }^{14}$. Therefore, open surgery remains our institutional choice. The number of procedures performed in recent years has been increasing. It has already been reported that the effect of high-volume centers in the evolution of patients involves a reduction in perioperative morbidity and mortality.

Several limitations of this study include that this was a single institution and single surgeon experience, an important number of patients did not attend theiffollow-up in our institution.

\section{Conclusion}

Negative prognosis predictors in our study include the presence of previous comorbidities, positive resection margins, and post-operative weight loss. Pancreatic fistula is the most feared complication? no technique has proven to be a permanent solution to 
this problem. The end-to-end telescope anastomosis with duct-to-mucosa anastomosis and cannulation of the pancreatic duct appears to have a lower fistula rate than reported before.

\section{Acknowledgments}

We thank Sergio Lozano-Rodriguez for his help in editing the manuscript.

\section{Conflicts of interest}

The authors declare that they have no conflicts of interest.

\section{Funding}

No grants or funding were received.

\section{Ethical disclosures}

Protection of human and animal subjects. The authors declare that no experiments were performed on humans or animals for this study.

Confidentiality of data. The authors declare that they have followed the protocols of their work center on the publication of patient data.
Right to privacy and informed consent. The authors declare that no patient data appear in this article.

\section{References}

1. Jemal A, Siegel R, Ward E, et al. Cancer statistics, 2008. CA Cancer J Clin. 2008;58:71-96.

2. Hidalgo M. Pancreatic cancer. N Engl J Med. 2010;362:1605-17.

3. Crile G Jr. The advantages of bypass operations over radical pancreatoduodenectomy in the treatment of pancreatic carcinoma. Surg Gynecol Obstet. 1970;130:1049-53.

4. Rocca A, Calise F, Marino G, et al. Primary giant hepatic neuroendocrine carcinoma: a case report. Int J Surg. 2014;12 Suppl 1:S218-2P

5. Riall TS, Cameron JL, Lillemoe KD, et al. Resected periampullary adenocarcinoma: 5-year survivors and their 6-to 10-year follow-up. Sufgery. 2006;140:764-72

6. Schmidt CM, Powell ES, Yiannoutsos CT, et al. Pancreaticoduodenectomy: a 20-year experience in 516 patients. Arch Surg. 2004;139:718-25.

7. DeOliveira ML, Winter JM, Schafer M, et al. Assessment of complications after pancreatic surgery: a novel grading system applied to 633 patients undergoing pancreaticoduodenectomy. Ann Surg. 2006;244:931-7

8. Balzano G, Zerbi A, Capretti G, et al. Effect of hospital volume on outcome of pancreaticoduodenectomy in Italy. Br J Surg. 2008;95:357-62.

9. Armstrong T, Strommer L, Ruiz-Jasbon F, et al. Pancreaticoduodenectomy for peri-ampullary neoplasia leads to specific micronutrient deficiencies. Pancreatology. 2007;7:37-44.

10. Whipple AO. Pancreaticoduodenectomy for islet carcinoma: a five-year follow-up. Ann Surg. 1945;121:847-52.

11. Riall TS, Kuo Y, Towsend CM, et al. The Impact of Age on Surgical Resection Rates And Long-Term Survival in Patients with Locoregional Pancreatic Cancer. Vol. 151. Submitted to the $4^{\text {th }}$ Annual Academic Surgical Congress; 2008. p. 284.

12. Cameron JL, He J. Two thousand consecutive pancreaticoduodenectomies. J Am Coll Surg. 2015;220:530-6.

13. Kleespies A, Albertsmeier M, Obeidat F, et al. The challenge of pancreatic anastomosis. Langenbecks Arch Surg. 2008:393:459-71.

14. Dokmak S, Ftériche FS, Aussilhou B, et al. Laparoscopic pancreaticoduodenectomy should not be routine for resection of periampullary tumors. J Am Coll Surg. 2015;220:831-8. 